\title{
Protocol for high-sensitivity/long linear-range spectrofluorimetric DNA quantification using ethidium bromide
}

\author{
Veronica Bonasera, Saverio Alberti, and Andrea Sacchetti \\ G. d'Annunzio University Foundation, Chieti, Italy \\ BioTechniques 43:173-176 (August 2007) \\ doi 10.2144/000112500
}

\begin{abstract}
Ethidium bromide (EtBr) is the most widely used fluorescent dye in nucleic acid gel electrophoresis since decades. However, it has been essentially forgotten in DNA quantification by spectrofluorimetry. While investigating sensitivity and dynamic range of available fluorochromes, we found that EtBr permits much more sensitive fluorimetric measurements than previously thought. We report here a revised, accurate, and easy-to-use protocol for EtBrbased DNA quantification in solution, which usefully complements the widely used indirect quantification on agarose gels.
\end{abstract}

The first studies on ethidium bromide (EtBr) for nucleic acid quantification date back to the mid-1960s (1) and have been followed by occasional reports over the years $(2,3)$. Conventional knowledge on spectrofluorimetric DNA quantification using $\mathrm{EtBr}$ indicates that the best results are obtained with $5 \mu \mathrm{g} / \mathrm{mL} \mathrm{EtBr}$, using excitation at 546 or $302 \mathrm{~nm}$. This allows reaching a detection limit of 100 $\mathrm{ng} / \mathrm{mL}$ of double-stranded DNA (2). Our studies indicate that these parameters are largely suboptimal, and that a significantly higher sensitivity can be obtained by lowering the concentration of $\mathrm{EtBr}$ and using a more efficient excitation in the ultraviolet (UV) region. We have also developed a novel ratiometric approach that allows to further improve the sensitivity of the assay.

To reach the best signal-to-noise ratios, EtBr (Sigma-Aldrich, St. Louis, MO, USA) was tested at different concentrations $(0.1,0.5$, and $2.5 \mu \mathrm{g} /$ $\mathrm{mL}$ ), as previously done for Hoechst 33258 (2). EtBr was diluted in TrisEDTA (TE) buffer ( $1 \mathrm{mM}$ Tris- $\mathrm{HCl}, 0.1$ mM EDTA, $\mathrm{pH}$ 7.4) in a final volume of $200 \mu \mathrm{L} /$ well. Spectrofluorimetry microplates (OptiPlate ${ }^{\text {TM}}-96$ white opaque 96-well microplate; PerkinElmer, Waltham, MA, USA) were utilized for all the assays presented here. However, conveniently, almost equivalent results were obtained using standard tissue culture flat-bottom 96-well plates (BD Falcon ${ }^{\mathrm{TM}}$ 96-well microplates;
BD Biosciences, Franklin Lakes, NJ, USA). Genomic DNA from peripheral blood leukocytes $(0.24 \mathrm{ng} /$ well to 2 $\mu \mathrm{g} /$ well) prepared as previously described (4) was added to the wells, and fluorescence was measured immediately thereafter. Fluorescent readings were performed on a SpectraMax ${ }^{\circledR}$ Gemini XS spectrofluorimeter (Molecular Devices, Sunnyvale, CA, USA).

In Figure 1 we show the UV region excitation spectra of free and DNAbound $\mathrm{EtBr}$ and demonstrate the range of linear measurements of DNA concentrations. Excitation peaks were at 286 and $270 \mathrm{~nm}$ for free and DNAbound ethidium, respectively (Figure 1A). Highest emission was at $605 \mathrm{~nm}$. We found the highest fluorescence increase of DNA-bound versus free $\mathrm{EtBr}$ (about 40-fold) and the best signalto-noise ratio at $250 \mathrm{~nm}$ (Figure 1B and data not shown). A corresponding ratio of bound versus free signal was observed at 364-nm excitation, but at the price of a lower signal-to-noise ratio. On the other hand, we observed a significantly worse performance when exciting at $546 \mathrm{~nm}$ (2). Excitation at $250 \mathrm{~nm} /$ emission at $605 \mathrm{~nm}$ were chosen for all subsequent studies. This wavelength choice minimized chances of undesired bleed-through of excitation light through the diffraction grating monochromator, which can be particularly relevant when excitation is close to half of the emission wavelength chosen. Additionally, a 590-nm longpass filter was utilized before light collection by the photomultiplier.

A concentration of $0.5 \mu \mathrm{g} / \mathrm{mL} \mathrm{EtBr}$ allowed to reach a detection limit of 2 ng DNA/well $(10 \mathrm{ng} / \mathrm{mL})$, with a linear range of measurements from 4-250 ng/well (20-1250 ng/mL) (Figure 1C). The standard error of the mean (SEM) of five independent experiments (Figure 1C) was shown to range between $0.4 \%$ (125-250 ng/well) and 2.2\% (4-8 ng/ well) of the respective means. Higher concentrations of EtBr extended the linear range of measurements to higher amounts of DNA (from $15 \mathrm{ng}$ DNA/well to $1250 \mathrm{ng} / \mathrm{well}$ for $2.5 \mu \mathrm{g} / \mathrm{mL} \mathrm{EtBr}$ ). However, this was associated with a considerable loss in sensitivity (data not shown). On the other hand, sensitivity was slightly improved using $0.1 \mu \mathrm{g} / \mathrm{mL}$ EtBr (1 ng DNA/well; 5 ng/mL), but, the amplitude of the linear range was significantly reduced ( 2 to $50 \mathrm{ng} / \mathrm{well}$; Figure 1D). Hence, for most purposes a good compromise between sensitivity and amplitude of the linear range can be obtained with $0.5 \mu \mathrm{g} / \mathrm{mL} \mathrm{EtBr}$. Fluorescence measurements on different dilution series of a specific DNA sample were found to be remarkably reproducible. Equally reproducible were fluorescence measurements on different or independently quantified sources of DNA (Figure 1 and data not shown).

As DNA binding induces both a fluorescence increase and a spectral shift of ethidium fluorescence (the excitation peak shifts from 286 to 270 $\mathrm{nm}$ ), we also investigated if a ratiometric approach could increase the sensitivity of EtBr-based measurements. Ratiometric methods are commonly used in spectrofluorimetry, as they provide a stringent internal standard, leading to more accurate measurements of both quantitative and qualitative fluorescent changes. Plotting the ratio between the fluorescent emissions of EtBr excitated at $250 \mathrm{~nm}$ versus 286 $\mathrm{nm}$, we extended the linear range of measurements to lower DNA amounts and obtained a significant gain in sensitivity (2- to 4-fold) at any EtBr concentration tested. The lowest detection limit of ratiometric measurements was $0.25 \mathrm{ng}$ DNA/well with $0.1 \mu \mathrm{g} / \mathrm{mL}$ 


\section{Benchmarks}

$\mathrm{EtBr}$ (Figure 1E), with a linear range of $0.5-8 \mathrm{ng} /$ well $(2.5-40 \mathrm{ng} / \mathrm{mL})$.

Parallel measurements were performed using quartz cuvettes (SUPRASIL ${ }^{\circledR}$ quartz cuvettes; Hellma GmbH \& Co, Müllheim, Germany) and a PerkinElmer LS 45 Luminescence Spectrometer. As expected, somewhat better measurements were obtained, due to the better light path (i.e., absence of meniscus and reduced light scattering). However, the improvement in sensitivity was found marginal ( $<2$-fold). The $R^{2}$ (correlation coefficient) of serially diluted DNA in plate readings was found to be 0.996 (Figure 1C, inset); that of the corresponding cuvettes readings was a comparable 0.993 . These findings and the more cumbersome handling of DNA-EtBr dilutions discouraged the use of cuvettes when several dozen samples had to be measured. It should be noted that disposable plastic cuvettes cannot be used for excitation in the UV region around $250 \mathrm{~nm}$. In this case, excitation at $364 \mathrm{~nm}$ is advisable.

Fluorescence measurements on different dilution series of a specific DNA sample and across different DNA samples, all previously quantified by spectrophotometry, were found to be highly reproducible. Fluorescence measurements closely matched the expected amount of DNA contained in a well down to $0.5 \mathrm{ng}$ DNA/well $(0.1 \mu \mathrm{g} /$ $\mathrm{mL} \mathrm{EtBr}$; Figure 1E). The shape of the excitation spectra of DNA/EtBr samples were as expected from mixtures of the two corresponding spectra at different ratios (Figure 1B).

In summary, our data render better justice to $\mathrm{EtBr}$, a fluorescent dye long forgotten in spectrofluorimetric DNA quantification. We found that the choice of appropriate $\mathrm{EtBr}$ concentrations and better excitation/emission wavelengths, as well as the use of ratiometric measurements make the EtBr-based spectrofluorimetric DNA quantification significantly more performing than currently thought $(3,5,6)$.

\section{ACKNOWLEDGMENTS}

The financial support of the Fondazione of the Cassa di Risparmio della Provincia di Chieti, of the Association for the Application of
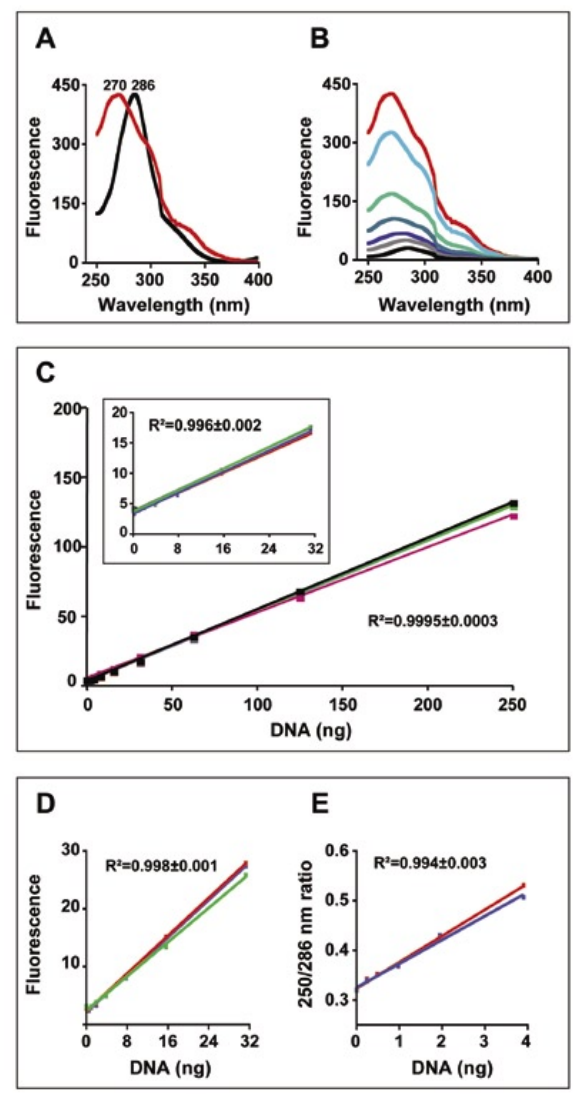

Biotechnology in Oncology (ABO, grant no. VE01D0019), and of the Italian Ministry for the University and Research (FIRB Postgenomica, grant no. RBNE0157EH) is gratefully acknowledged.

\section{COMPETING INTERESTS STATEMENT}

The authors declare no competing interests.

\section{REFERENCES}

1. Le Pecq, J.B. and C. Paoletti. 1966. A new fluorometric method for RNA and DNA determination. Anal. Biochem. 17:100-107.

2. Gallagher, S.R. and P.R. Desjardins. 2006. Quantitation of DNA and RNA with absorption and fluorescence spectroscopy, $\mathrm{p}$. A3.D.1-A3.D3 In Ausubel, F.M, R. Brent, R.E. Kingston, D.D. Moore, J.G. Seidman, J.A. Smith, and K. Struhl (Eds.) Current Protocols in Molecular Biology, vol 3. John Wiley \& Sons, New York.

3. Rengarajan, K., S.M. Cristol, M. Mehta, and J.M. Nickerson. 2002. Quantifying DNA concentrations using fluorometry:
Figure 1. DNA quantification by fluorescence emission of intercalated ethidium bromide (EtBr). (A) Fluorescence excitation spectra of DNA-bound $\mathrm{EtBr}$ (red line) and free EtBr (black line). Maxima are at $270 \mathrm{~nm}$ (DNA-bound $\mathrm{EtBr}$ ) and at $286 \mathrm{~nm}$ (free EtBr). (B) Fluorescence excitation spectra of free EtBr $0.5 \mu \mathrm{g} / \mathrm{mL}$ (black bottom line) versus $\mathrm{EtBr}$ bound to increasing amounts of DNA up to $1000 \mathrm{ng}$ [15.6 ng, gray; $31.3 \mathrm{ng}$, blue; $62.5 \mathrm{ng}$, dark green; $125 \mathrm{ng}$, light green; $250 \mathrm{ng}$, cyan; $1000 \mathrm{ng}$, red (the emission spectrum of 500 ng overlapped with that of $1000 \mathrm{ng}$ )]. (C) Linear relationship between DNA amounts and fluorescence emission for $0.5 \mu \mathrm{g} / \mathrm{mL}$ EtBr. Differently colored curves represent five independent experiments; violet and blue data sets are hidden by overlapping datapoints. (inset) higher resolution graph of the lowest DNA amounts (0-32 ng/well); differently colored curves represent four independent experiments. Excitation, $250 \mathrm{~nm}$; emission, $605 \mathrm{~nm}$. (D) Linear relationship between DNA amounts and fluorescence emission for $0.1 \mu \mathrm{g} / \mathrm{mL}$ $\mathrm{EtBr}$. Data from three independent experiments are reported. Excitation, $250 \mathrm{~nm}$; emission, $605 \mathrm{~nm}$. (E) Linear relationship between DNA amount and the fluorescent emission of EtBr excitated at 250 $\mathrm{nm}$ versus $286 \mathrm{~nm}$. Differently colored curves represent two independent experiments. Average correlation coefficients of each data set are reported (mean $R^{2} \pm \mathrm{SD}$ ). Fluorescence unit scales in the $y$ axis were adapted to the absolute signals recorded in the diverse assays.

a comparison of fluorophores. Mol. Vis. 8:416-421

4. Alberti, S. and M. Fornaro. 1990. Higher transfection efficency of genomic DNA purified with a guanidinium-thiocyanate-based procedure. Nucleic Acids Res. 18:351-353.

5. Leggate, J., R. Allain, L. Isaac, and B.W. Blais. 2006. Microplate fluorescence assay for the quantification of double stranded DNA using SYBR Green I dye. Biotechnol. Lett. 28:1587-1594.

6. Singer, V.L., L.J. Jones, S.T. Yue, and R.P. Haugland. 1997. Characterization of PicoGreen reagent and development of a fluorescence-based solution assay for doublestranded DNA quantitation. Anal. Biochem. 249:228-238.

Received 17 April 2007; accepted 13 June 2007.

Address correspondence to Prof. Saverio Alberti, Unit of Cancer Pathology, Center of Excellence in Research on Aging, University G. d'Annunzio, Via Colle dell' Ara, 66013 Chieti Scalo, Italy. e-mail: s.alberti@unich.it

To purchase reprints of this article, contact: Reprints@BioTechniques.com 